\title{
Surgical emphysema, bilateral pneumothorax, pneumomediastinum and pneumoperitoneum complicating intubation for anaesthesia
}

\author{
J. K. SCOTT \\ M.B., Ch.B., F.R.C.P.E., D.P.H.
}

J. VINER

M.B., Ch.B.

\section{Pinderfields General Hospital, Wakefield, and The General Hospital, Dewsbury}

\begin{abstract}
Summary
A combination of surgical emphysema, bilateral pneumothorax, pneumomediastinum and pneumoperitoneum complicating anaesthesia using endotracheal intubation has been reported only once before. Its occurrence twice in a recent period of 4 months at one hospital suggests that it may not be rare. Recognition of the early signs should enable steps to be taken before irreversible cerebral damage has occurred.
\end{abstract}

\section{Introduction}

Anaesthesia using endotracheal intubation is now almost universally practised and the incidence of complications is extremely low (McGovern, FitzHugh and Edgemon, 1971). However, in the space of 4 months we have seen two patients with severe complications which have been reported only once before (Suzuki et al., 1967). This is a combination of surgical emphysema, bilateral pneumothorax, pneumomediastinum and pneumoperitoneum. Various authors have reported surgical emphysema (Smith, Pooland Volpitto, 1959), pneumothorax(Graulauand Phelps, 1972; Freeman, 1972; Vogt-Moykopf and Muller, 1966), surgical emphysema and pneumomediastinum (Manheim and Nevin, 1971), pneumothorax and pneumomediastinum (Fearon et al., 1966) and combined surgical emphysema, pneumothorax and pneumomediastinum (Golding, Urban and Steen, 1966), Our experience of these complications makes it clear that early recognition and immediate action is necessary to avoid loss of life and for this reason they are now described.

\section{Case report 1}

A child aged 2 years developed symptoms and signs suggestive of a cerebral tumour and carotid angiography was arranged under general anaesthesia. Some difficulty was encountered in insertion of the endotracheal tube and shortly afterwards the child developed swelling of the neck and severe breathlessness. One of us was called to the theatre and found a very cyanosed and breathless child with surgical emphysema of the neck and upper chest. He was making spasmodic attempts at breathing and oxygen was being administered under pressure through the endotracheal tube. Breath sounds were absent on auscultation and a chest radiograph (Figs 1 and 2) revealed collapse of both lungs with bilateral pneumothoraces, pneumomediastinum and a large pneumoperitoneum. Air was quickly aspirated from both sides of the chest using a syringe and needle, but the child's condition did not improve until the endotracheal tube was removed and oxygen administration stopped. A further chest radiograph not long afterwards showed complete re-expansion of the left lung and almost complete re-expansion of the right with aeration of the lungs and disappearance of the pneumomediastinum and pneumoperitoneum and the following day the chest radiograph was completely normal. The child later died during an exploratory operation which revealed a large cerebrat tumour.

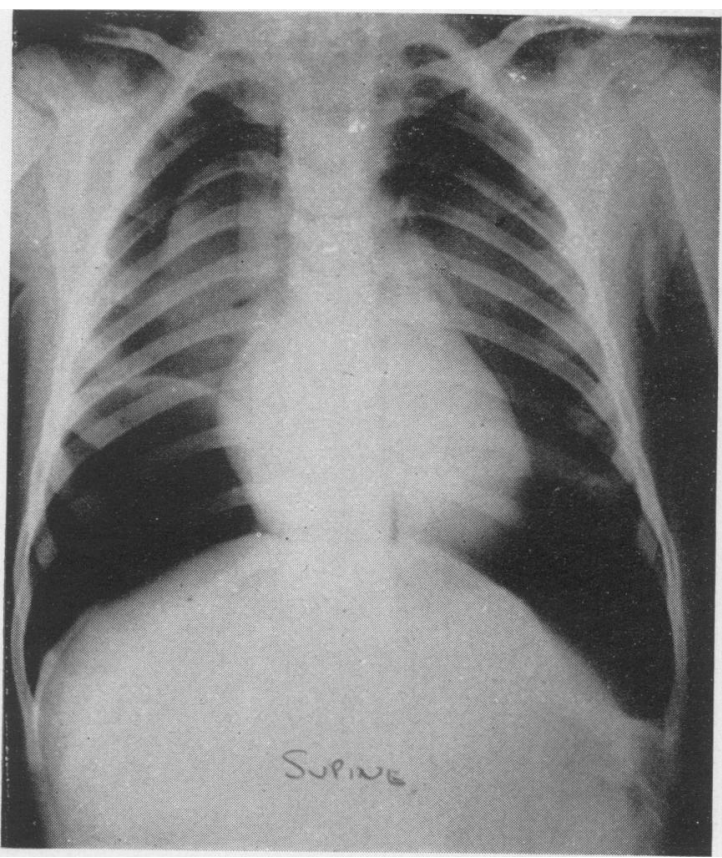

FIG. 1. 

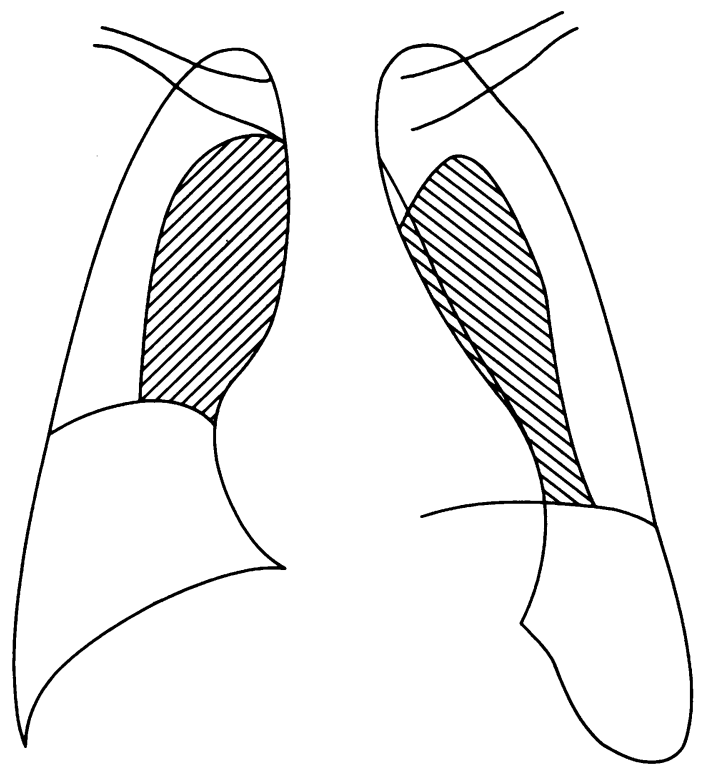

FIG. 2.

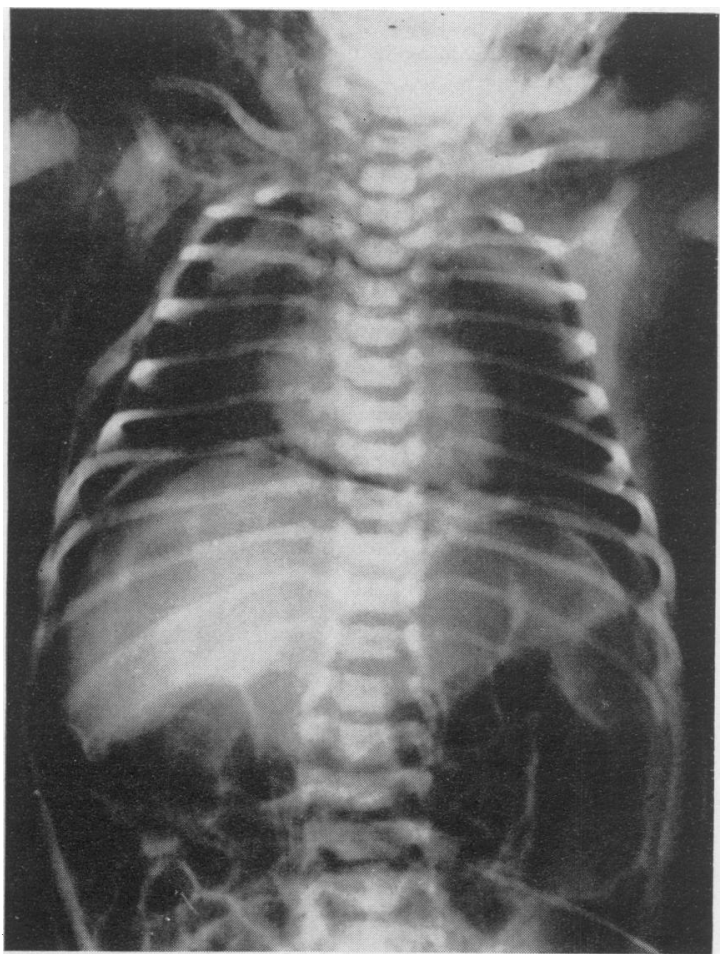

FIG. 3.

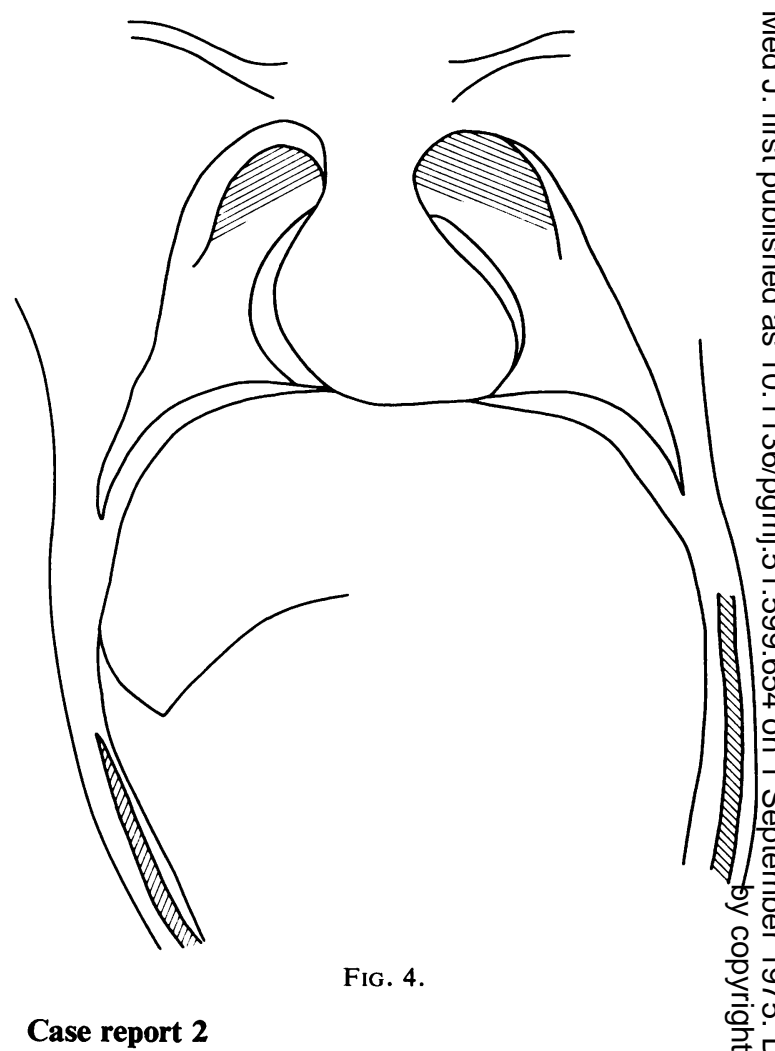

This child was found to have a lumbar meningomyelocele at birth and was immediately transferred to the neuro-surgical unit for a repair operation the same day. There was some difficulty in insertion of the endotracheal tube and during the operation the child developed severe surgical emphysema affecting the whole body including the scalp and lower limbs, accompanied by severe cyanosis, spasmodic breathing and a distended abdomen. The extent and severity of the surgical emphysema was remarkable. A chest radiograph (Figs 3 and 4) demonstrated severe inflation of the body, with bilateral pneumothoraces and collapse of both upper lobes, pneumomediastinum and gross pneumoperitoneum. Air was aspirated from both sides of the chest using a syringe and needle and, later, a canula but improvement in the child's condition did not take place until the endotracheal tube was removed and oxygen inflation discontinued. A chest radiograph four hours later showed both lungs almost fully re-expanded and aerated and the infant's condition was normal. The surgical emphysema had almost completely disappeared. Three weeks later the infant was again intubated for anaesthesia for insertion of a ventriculoperitoneal shunt and no difficulty was encountered. Three months later the child died. Autopsy was not performed. 


\section{Discussion}

Smith et al. (1959) demonstrated in cadavers that it was easy to produce subcutaneous emphysema by making a small incision $(0.95 \mathrm{~cm}$ long) just through the mucosa of the piriform sinus and subjecting the pharynx to a moderate pressure of oxygen $(30 \mathrm{mmHg})$ for less than $1 \mathrm{~min}$ by means of a mask. Johannides and Tsoulos (1930), in experiments with dogs, showed that a simple increase in intrabronchial air pressure could produce initially a pneumothorax then air would escape to the subcutaneous and interstitial tissues, and, via the oesophageal hiatus of the diaphragm, to the retroperitoneal spaces. They concluded that a moderate increase in pressure was sufficient to rupture the pleura at the periphery of the bronchial tree.

The further development of pneumoperitoneum is less easily explained. Therapeutic pneumoperitoneum in the past was complicated only on rare occasions by pneumothorax (Crofts, 1954) or mediastinal emphysema (Breathnach, 1955) and in the vast majority of cases quite high positive pressures could be maintained for months or years without complication. Perhaps the most likely explanation is that advanced by Johannides and Tsoulos (1930) who, during their experiments on dogs described above, found that after air had reached the retroperitoneal tissues a bulla frequently formed in the region of the perirenal areolar tissues which in turn ruptured to allow air to escape into the abdominal cavity.

The likely mechanism of the complications in the two patients described, therefore, is that while the lungs were being inflated under pressure, oxygen was forced into the pleural cavity and interstitial tissues either through a laceration of the mucosa of the trachea caused by insertion of the tuke or by rupture of alveolar walls as a result of a high inflating pressure. In the two patients described, the endotracheal tube used was the soft type requiring the use of a metal introducer. It is easy to see how this introducer might protrude from the end of the tube and cause damage to the mucosa. On the other hand, Thompson and Read (1968) during a thoracotomy operation found a tear in the membranous trachea and were surprised that there was no evidence of pneumothorax, pneumoperitoneum, subcutaneous or mediastinal emphysema. Perhaps the inflating pressure is more important than the breach of continuity of mucous membrane. Our two patients and that of Suzuki (1967) were under the age of 2.5 years and it may be that the risk of extensive inflation of interstitial tissues and body cavities is greater in young children.

Although this combination of complications has been reported only once before, it has occurred on two occasions within 4 months in one hospital. The risk involved is demonstrated graphically by the chest radiograph (Figs 3 and 4) which shows complete collapse of both lungs and it is highly unlikely that this stage could last for more than a brief period. The risk of brain damage or death must have been high.

The possibility that the use of an introducer with an endotracheal tube could damage the mucosa would have to be borne in mind when using this method. When air is being pumped into the lungs under pressure, especially by hand, when high pressures can be attained, it is clearly very important to watch for signs that the air is indeed going into the lungs, i.e. by observing chest expansion. Also it is important to watch for evidence that the air is not going where it should not go, e.g. into the subcutaneous tissues. If there is doubt, then the tube should be removed and a simple method of ventilation adopted.

\section{Acknowledgments}

We wish to thank Mrs E. Smith and Mrs S. Thomas for secretarial assistance in the preparation of this paper.

\section{References}

CROFTs, N.F. (1954) Pneumothorax complicating therapeutico pneumoperitoneum. Thorax, 9, 226.

BrEATHNACH, C.S. (1955) Mediastinal emphysema and itso occurrence in artificial pneumoperitoneum. Thorax, 10, 790

Fearon, B., MacDonald, R.E., Smith, C. \& Mitchell, D (1966) Airway problems in children following prolongeक endotracheal intubation. Annals of Otology, 75, 975.

FreEMAN, G.R. (1972) A comparative analysis of endotracheal intubation in neonates, children and adults: Complications, prevention and treatment. The Laryngoscope, 82, 1385.

Golding, M.R., Urban, B.J. \& Steen, S.N. (1966) Subcutaneous emphysema, pneumomediastinum and pneumothorax. British Journal of Anaesthesia, 38, 482.

Graulau, M.F. \& Phelps, McK. (1972) Bilateral pneumothorax and cardiovascular collapse on induction of anesthesia. Anesthesia and Analgesia, 51, 671.

Johannides, M. \& Tsoulos, G.D. (1930) The etiology of interstitial and mediastinal emphysema. Archives of Surgery, 21, 333.

Manheim, A. \& Nevin, J.E. (1971) A rare complication from a not-so-rare occurrence (endotracheal intubation). Southern Medical Journal, 64, 814.

MCGovern, F.H., Fitz-Hugh, G.S. \& Edgemon, L.J. (1971) The hazards of endotracheal intubation. Annals of Otology, 80, 556.

Smith, R.H., Pool, L.L. \& VolPitto, P.P. (1959) Subcutaneous emphysema as a complication of endotracheal intubation. Anesthesiology, 20, 714.

SUZUKI, H. et al. (1967) A case of pneumothorax, mediastinal and subcutaneous emphysema and pneumoperitoneum during induction of anaesthesia. Japanese Journal of Anaesthesiology, 16, 1108.

ThOMPSON, D.S. \& READ, R.C. (1968) Rupture of the trachea following intubation. Journal of the American Medical Association, 204, 995.

Vogt-Moykopf, I. \& Muller, C. (1966) Bilateral spontaneous pneumothorax as a result of intubation. Anesthesio$\log y, 37,25$. 